\title{
Correction to: Early hydration calorimetric study of the sewage sludge incinerated waste streams Portland cement-based binders: technological implications
}

\author{
Lidia Natalia Trusilewicz ${ }^{1}$ (1) $\cdot$ Wiesława Nocuń-Wczelik ${ }^{2} \cdot$ Piotr Górak $^{3} \cdot$ Piotr Woyciechowski ${ }^{4}$
}

Published online: 14 November 2019

๑) Akadémiai Kiadó, Budapest, Hungary 2019

\section{Correction to: Journal of Thermal Analysis and Calorimetry https://doi.org/10.1007/s10973-019-08784-7}

The original version of the article was improperly published online. In the consequence, the update of the article title was provided, which primordial form is as follows: "Early hydration calorimetric study of the sewage sludge incinerated waste streams Portland cement-based binders: technological implications". The original article has been corrected.

The original article can be found online at https://doi.org/10.1007/ s10973-019-08784-7.

Lidia Natalia Trusilewicz

lidiatrusilewicz@ymail.com

1 Research and Innovation Centre Pro-Akademia, 95-050 Konstantynów Łódzki, Poland

2 Faculty of Materials Science and Ceramics, AGH University of Science and Technology, 30-059 Kraków, Poland

3 Technology and Quality Management Group, Concrete Quality and Technology Team, CEMEX Poland Sp. o.o., 42-240 Rudniki, Poland

4 Faculty of Civil Engineering, Institute of Building Engineering, Warsaw University of Technology, 00-637 Warszawa, Poland 